\title{
Genome and Transcriptome Sequencing of Novel Pseudomonas sp. NLX-4 Strain Involved in Bio-Restoration of Over Exploited Mining \\ Sites
}

\section{Yanwen Wu}

Lakehead University - Thunder Bay Campus: Lakehead University

Ayyappa Kumar Sista Kameshwar

Lakehead University - Thunder Bay Campus: Lakehead University

\section{Bo Zhang}

University of Miami

Fei Fei Chen

Nanjing Forestry University

Wensheng Qin ( $\nabla$ wqin@lakeheadu.ca )

Lakehead University https://orcid.org/0000-0003-2178-4003

\section{Miaojing Meng}

Nanjing Forestry University

Jinchi Zhang

Nanjing Forestry University

\section{Research Article}

Keywords: Rock mining, Ecological restoration, Silicate rock-dissolution, Pseudomonas sp. NLX-4 strain, Genome sequencing, Transcriptome sequencing

Posted Date: December 13th, 2021

DOI: https://doi.org/10.21203/rs.3.rs-1091120/v1

License: (c) (i) This work is licensed under a Creative Commons Attribution 4.0 International License. Read Full License 


\section{Abstract}

Microbial weathering processes can significantly promote soil properties and enhance rock to soil ratio. Some soil-inhabiting bacteria exhibit efficient rock-dissolution abilities by releasing organic acids and other chemical elements from the silicate rocks. However, our understanding of the molecular mechanisms involved during bacterial rock-dissolution is still limited. In this study, we performed silicate rock-dissolution experiments on a novel Pseudomonas sp. NLX-4 strain isolated from an over-exploited mining site. The results revealed that Pseudomonas sp. NLX-4 strain efficiently accelerates the dissolution of silicate rocks by secreting amino acids, exopolysaccharides, and organic acids. Through employing genome and transcriptome sequencing (RNA-seq), we identified the major regulatory genes. Specifically, fifteen differentially expressed genes (DEGs) encoding for siderophore transport, EPS and amino acids synthesis, organic acids metabolism, and bacterial resistance to adverse environmental conditions were highly up-regulated in silicate rock cultures of NLX-4 strain. Our study proposes a novel bacterial based approach for improving the ecological restoration of over-exploited rock mining-sites.

\section{Introduction}

About $90 \%$ of the earth crust is composed of silicate minerals and these silicates are building blocks of most rock types (Prothero and Schwab, 2004). Human encroachments of earth surface in the form of mining have severely destroyed the ecology of the mining areas, causing soil erosion, exposure of bedrock and loss of productivity (Comino et al., 2016; Erkossa et al., 2015; Ochoa-Cueva et al., 2015). The area of soil and water loss in mining sites caused by overexploitation is increasing at a rate of $1.5 \times 10^{4} \mathrm{~km}^{2} \mathrm{yr}^{-1}$, and more than $20 \%$ of these areas have been classified as rocky desertification (Balland-Bolou-Bi and Poszwa, 2012). Studies were being conducted to resolve the environmental destruction of these mining sites by developing efficient ecological restoration technologies (Jeffries et al., 2003). Spraying material on the surface of exposed rocks supplemented with plant seeds, soil and nutrients, which is known as external-soil spray seeding technology, is one of the most efficient and highly implemented approaches in the ecological restoration of mining areas (Russell, 2002). However, the current spraying material cannot break down rocks to continuously provide essential nutrients for plant growth. Therefore, soil formation for sustainable growth of plant is the key to solve the problem in long-term maintenance of external-soil spray seeding technology.

Microorganisms are widely present in natural environments. They break down the organic and inorganic compounds, and release them back into the environment as metabolic compounds (Bouwer and Zehnder, 1993). This process is known as bioweathering that promotes the rock-to-soil transition and improves the soil environment for plant growth (Gleeson et al., 2006; Vandevivere et al., 1994). Studies have reported that microorganisms accelerate the process of bioweathering through chemical dissolution, formation of rock-biofilm and chelating reactions (Finlay et al., 2009; Lian et al., 2008). Various microbial proteins have been proven that play vital roles in the bioweathering of rocks. For example, the bacterial membrane transport/channel proteins are crucial in increasing the absorption and transportation rate of mineral elements during the process of rock dissolution (Chen et al., 2008). Conversely, the unavailability of minerals and nutrients in rocky areas forces the microorganisms to regulate the expression of corresponding genes that control the synthesis of proteins involved in rock solubilization (Alahari and Apte, 2004).

Comprehensive understanding of the microbial gene regulation is of great concern in developing efficient microorganisms with rockdissolving abilities (Finlay et al., 2009). Xiao et al (2012a) have conducted a PCR-based suppression-subtractive hybridization (SSH) experiments for exploring the differential expression of cDNA fragments in the control and experimental transcriptomes of Aspergillus fumigatus, cultured on potassium supplemented rock-dissolution growth medium (Xiao et al., 2012c). Xiao et al (2012b) have also conducted a two-dimensional gel electrophoresis (2DGE) to understand the expression patterns of Bacillus mucilaginosus and its extracellular proteins secreted during the process of potassium rock dissolution (Xiao et al., 2012a). Nevertheless, it is difficult to draw convincing conclusions by analyzing the effect of individual factors on few candidate genes. Therefore, genome-wide transcriptome sequencing (RNA-seq) should be employed to capture the cellular snapshot of a rock-dissolving microorganisms at a given conditions (Kawahara et al., 2012).

Next generation sequencing technologies have been applied for analyzing and revealing the complete gene expression patterns of an organism for understanding the molecular mechanisms underlying its biological process (Kawahara et al., 2012; Wang et al., 2009). Wang et al (2015) have conducted a high-throughput RNA sequencing study to understand the molecular mechanisms of potassium feldspardissolving Aspergillus niger (Wang et al., 2015). The A. niger genes encoding for proteins involved in synthesis and transportation of organic acids, polysaccharides, cystathionine beta-synthase, cysteine synthase, and glutathione synthase were found to be highly upregulated (Wang et al., 2015). However, studies related to microbial weathering of silicate minerals were not conducted till date. Our present research is focused on understanding and exploring the effects and participating genes of an efficient silicate rock-dissolving bacterial strain. We have isolated 22 bacterial strains from a disturbed silicate rock mining site. The most efficient rock-dissolving 
bacterium was screened out to understand the molecular complexities of silicate rock solubilization. We have conducted a whole-genome sequencing followed by genome-wide transcriptome analysis and validated the results using real-time fluorescent quantitative PCR (RTqPCR) (Jiang et al., 2011). We propose that the experimental and sequencing data generated and analyzed in this study provide the efficient bacterial and genetic resources to improve the external-soil spray seeding technology for silicate rock mining areas.

\section{Materials And Methods Rock samples}

The silicate rock samples used in our study were obtained from Mount Lu $\left(29^{\circ} 26^{\prime}-29^{\circ} 41^{\prime} \mathrm{N}, 115^{\circ} 52^{\prime}-116^{\circ} 08^{\prime} \mathrm{E}\right)$ in Jiangxi Province, southeast region in China (Fig. S1). This area was a typical overexploited silicate rock mining site with severely damaged ecological environment. The rock samples were fully rinsed in distilled water, dried and ground for 200 mesh sieve (Wu et al., 2017c). We have used Xray diffractometer (XRD, ARL EQUINOX 1000, Thermo Fisher Scientific, USA) to analyze the composition of the rock samples. We have also conducted a rock mineral sheer analysis of the rock samples.

\section{Screening of microbial strains}

Bacterial strains were isolated from the soil around the weathered rocks in Mount Lu using continuous gradient dilution method (Wu et al., 2017b). The isolated bacteria were cultured on Alexander Rove agar plates ( $5.0 \mathrm{~g}$ sucrose, $2.0 \mathrm{~g} \mathrm{Na}_{2} \mathrm{HPO}_{4}, 0.5 \mathrm{~g} \mathrm{MgSO}_{4} \cdot 7 \mathrm{H}_{2} \mathrm{O}, 0.005 \mathrm{~g}$ $\mathrm{FeCl}_{3}, 0.1 \mathrm{~g} \mathrm{CaCO}_{3}, \mathrm{l} .0 \mathrm{~g}$ rock sample, $15.0 \mathrm{~g}$ agar, $1000 \mathrm{~mL}$ deionized water). Approximately, $200 \mu \mathrm{L}$ of each dilution $\left(10^{-4}, 10^{-5}, 10^{-6}\right)$ was spread onto the surface of Alexander Rove agar plate. The inoculated plates were incubated at $28^{\circ} \mathrm{C}$ for $24-72 \mathrm{~h}$ to isolate individual colonies based on their size, color and morphology. Selected colonies were further purified using standard re-culturing techniques.

Each bacterial isolate was then tested for their capacity to produce indoleacetic acid (IAA) and siderophore, using the standard Salkowski colorimetric method and CAS assay respectively (Bric et al., 1991). The CAS assay was monitored using a spectrophotometer set at an absorbance of 630-nm, the treatment group (with bacteria) and control group (without bacteria) were represented as A and Ar respectively. The siderophore production was calculated as $\mathrm{A} / \mathrm{Ar}$ ratio (represented as $+/-$ ), the $\mathrm{A} / \mathrm{Ar}$ ratio is inversely proportional to the siderophore production thus, lower A/Ar ratio represents more siderophore production (Wu et al., 2019). Strains with more than $10 \mathrm{mg} \mathrm{L}^{-1}$ IAA and +++ siderophore productions were chosen for further experiments.

The above selected bacterial isolates were cultured in $10 \mathrm{~mL}$ Luria-Bertani broth (LB) medium incubated for $24 \mathrm{~h}$ at $180 \mathrm{rpm}$ in a shaking incubator. After $24 \mathrm{~h}, 1.0 \mathrm{~mL}$ of each isolate was inoculated into a conical flask containing $20 \mathrm{~mL}$ of fermentation medium ( $10 \mathrm{~g}$

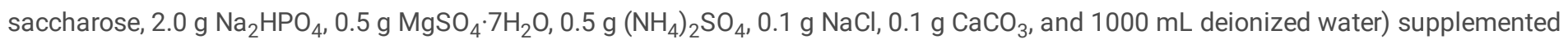
with $0.2 \mathrm{~g}$ silicate rock sample. The inoculated samples were incubated at $30^{\circ} \mathrm{C}$ with $180 \mathrm{rpm}$ for 7 days in a shaking incubator, conical flasks with $1.0 \mathrm{~mL}$ of inactivated isolates are considered as control (Wu et al., 2017c). The amount of $\mathrm{SiO}_{2}$ released from rock sample was determined using the standard silico-molybdenum blue spectrophotometric method (Meyer and Bloom, 1993). The NLX-4 strain which exhibited excellent IAA, siderophore and $\mathrm{SiO}_{2}$ releasing abilities was selected for genomic analysis.

\section{Identification of strain NLX-4}

Genomic DNA of NLX-4 strain was successfully extracted using CTAB method (Wu et al., 2017a). The 16S rRNA gene was PCR amplified using the following forward 27F (5'-AGAGTTTGATCC/ATGGCTCAG-3') and reverse primers1492R (5'-TACGGTTACCTTGTTA CGACTT-3'). The PCR products were verified using $1 \%$ agarose gel, and further sequenced by Genscript Co. LTD (Nanjing, China). The 16S rRNA gene sequence of NLX-4 strain was submitted to the NCBI (http://blast.ncbi.nlm.nih.gov/) database for identifying the phylogenetic closeness of the NLX-4 strain with others using BLAST. The phylogenetic relationship of NLX-4 strain was analyzed using MEGA 7.0 software, using Neighbour-joining phylogenetic tree method with Bootstrap values greater than $50 \%$ and 1000 replications were used for generating the phylogenetic tree (Sohpal et al., 2010).

\section{Rock-dissolution experiments}

The culture medium supplemented with $5.0 \mathrm{~g} \mathrm{~L}^{-1}$ silicate rock sample (sole $\mathrm{K}^{+}$source) was inoculated with NLX-4 strain and incubated at $30^{\circ} \mathrm{C}$ with $180 \mathrm{rpm}$ in a shaking incubator for different time periods ranging from $0,2,5,9,12,15,22$, and 30 days respectively. The culture medium was regularly monitored (the above mentioned time periods) for determining the concentration of $\mathrm{K}^{+}$and $\mathrm{Al}^{3+}$ ions, using inductively coupled plasma-atomic emission spectrometry (ICP-AES, Vista MPX, Varian, USA) as per the protocol reported by Wu et al. (2017c) and Kanicky and Mermet (1997). The concentration of Si ion released from the rock cultures was measured using the silicomolybdenum blue spectrophotometric method as mentioned above. The exopolysaccharides (EPS) secreted by NLX-4 strain was 
determined using the standard ethanol precipitation method (Sambrook and Russell, 2006). Amino acids and organic acids were analyzed using high performance liquid chromatography (HPLC, 1260 Infinity, Agilent Technologies, USA) using the well-established protocols (Wu et al., 2017b). The rock culture samples inoculated with inactivated NLX-4 strain was considered as control. We have also determined the particle diameter of the rock samples by retrieving the bacteria-rock mixtures and the rocks were separated based on the median particle diameter $\left(D_{50}\right)$ and analyzed using laser particle size analyser (LDSA, S3500 SI, Microtrac, USA) (Wu et al., 2017c). The particle diameter variations (PDV) were calculated as the differences between the experimental group and the control group.

\section{Whole genome sequencing and assembly of NLX-4}

The genomic DNA of NLX-4 strain was extracted using the standard SDS-based method (Zhou et al., 1996) and sequenced using the Illumina Hiseq 4000 (Illumina, Inc., San Diego, CA) and PacBio RSIl sequencing platform (BGI, Beijing, China). The raw data produced by Illumina Hiseq 4000 were initially processed to obtain clean data by discarding the low-quality reads (reads containing more than 36 bases, reads with $\leq 20$ base-qualities, reads with ploy-N $\geq 9 \mathrm{bp}$, reads with adapter or duplication bases). Similarly, the raw data of NLX-4 genome obtained from PacBio RSII were filtered by removing the polymerase reads shorter than $100 \mathrm{bp}$ or the read mass less than 0.80 , then the subreads with length $\geq 1000 \mathrm{bp}$ and reads without adapters were extracted from filtered polymerase reads respectively. The clean reads obtained after filtering were assembled using RS_HGAP Assembly3 (SMRT Analysis v2.3.0). The correct K-mers were observed for the reads with deep sequencing (high frequency), while random sequencing error-containing K-mers were observed for reads with low read frequency (Li et al., 2010). The error correction method used in this study was based on K-mer frequency information. The K-mer size was determined by the genome size, read length, and supercomputer memory (Li et al., 2010), thus $\mathrm{K}=15 \mathrm{bp}$ was chosen here. The corrections of single-base error in contig were performed using two-round analysis methods to process the data from Illumina Hiseq 4000 . The firstround error correction method was carried out by soap SNP and soap Indel software, while the second-round of error correction was conducted by GATK analysis pipeline. The circle form by contigs was vilified by checking the overlap using SSPACE-LongRead to determine the subreads or corrected reads based on the data obtained from PacBio RSII (Boetzer and Pirovano, 2014). The assembly of the bacterial genome was inspected by: 1 ) comparing $100 \mathrm{X}$ clean data to the assembly result (reads utilization $>95 \%$, the depth of backward and forward bunches $>3 X$, the insert size of backward and forward bunches was distributed within the proper range, satisfied randomness, and the depth of single bunches $=0$ ); 2 ) carrying out the statistics of repetitive sequence (parameters were set as -e 1e-10); 3) performing GC-depth assessment. Gene annotation was mainly based on amino acid sequence alignment (Wyman et al., 2004). The amino acid sequence of the gene was compared with the BLAST database, and the corresponding functional annotation information was obtained. Since each of these sequence comparisons had more than one result, the optimal comparison was retained as the annotation of gene, so as to ensure its biological significance (Slater and Birney, 2005). All annotations were completed by using BLAST software to combine various databases, including Gene Ontology (GO), Clusters of Orthologous Group (COG), Kyoto Encyclopedia of Genes and Genomes (KEGG), Swiss-Prot, and NCBI non-redundant protein (nr).

\section{RNA extraction, library preparation and RNA-seq}

The NLX-4 strain samples cultured with rock sample $\left(5.0 \mathrm{~g} \mathrm{~L}^{-1}\right)$ growth medium was incubated at $30^{\circ} \mathrm{C}$ with $180 \mathrm{rpm}$ for $15 \mathrm{~d}$, while strain NLX-4 cultured in fermentation medium added with $0.3 \mathrm{~g} \mathrm{~L}^{-1} \mathrm{KCl}$ was set as control. To further investigate the molecular mechanisms resulting involved in rock-dissolution we have performed a genome-wide RNA sequencing. The total RNA extraction was performed using TRIzol® Invitrogen reagent (Invitrogen, Carlsbad, CA). The total RNA extraction of NLX-4 strain cultures were performed separately for the control and treated group cultures (Gómez-Lozano et al., 2012). RNA quality was analyzed using Agilent® bioanalyzer (Agilent 2100, Agilent Technologies, USA). Ribo-Zero rRNA removal kit (Illumina, Inc. San Diego, CA) was used for extracting total RNA devoid of rRNA. After extracting sequencing quality total RNA we have added fragmentation buffer was for breaking down the mRNA to short fragments. Taking these short fragments as templates, random hexamer-primers were used to synthesize the first-strand cDNA. The second-strand cDNA was synthesized using buffer supplemented with dATPs, dGTPs, dCTPs, dUTPs, RNase H and DNA polymerase I respectively after removing dNTPs. Short fragments were purified using the QiaQuick ${ }^{\circledR}$ PCR extraction kit (QIAGEN, Hilden, Germany) and later resolved using the elution buffer for repairing the ends of the strands and adding poly (A) tails. After that, the short fragments were connected with sequencing adapters. Then, the UNG enzyme was used to degrade the second-strand CDNA, followed by purifying the product using the MinElute ${ }^{\circledR}$ PCR Purification Kit (QIAGEN, Hilden, Germany) before the PCR amplification process. Thus, obtained mRNA library was sequenced using Illumina HiSeq2000 (Illumina, Inc., San Diego, CA).

\section{Bioinformatic analysis of NLX-4 transcriptome data}

Raw data produced by Illumina Hiseq 2000 were initially processed to obtain clean data by discarding the low-quality reads (reads containing adapter sequences, ploy- $\mathrm{N}$, or low-quality bases). Clean reads obtained after filtering were mapped to the NLX-4 reference genome (fully assembled genome of strain NLX-4) using SOAP2 (Li et al., 2009). Mismatches with no more than 5 bases were allowed 
during the process of alignment. Reads per kb per million reads (RPKM) method was used to calculate individual gene expression of the test and control samples (Mortazavi et al., 2008). The RPKM level data of control and treatment samples were also analyzed using edgeR, limma, and Glimma statistical analysis packages to obtain statistically significant DEGs (Audic and Claverie, 1997). DEGs with false discovery rate (FDR) $\leq 0.001$ and fold change ratio larger than 2 were chosen for gene ontology (GO) functional enrichment analysis and KEGG pathway analysis. Only the genes exhibiting the P-value $<0.05$ and Q-value $<0.05$ were considered as differentially expressed (Tribelli et al., 2015).

\section{Quantitative real-time PCR (RT-qPCR) validation}

We have specifically performed the RT-qPCR analysis using the significant list of differentially expressed RNA transcript sequences encoding for 5 metabolically important genes. The forward and reverse primers were designed using the Primer Premier 5.0 software (Table 1). RT-qPCR procedures were performed as previously suggested (Tribelli et al., 2015). The relative quantification of the control and test samples were performed by including three biological replications and the obtained gene expression results were normalized to the reference gene (16S rRNA). The differential expression of the subjected genes were calculated according to the standard $2^{-\Delta \Delta C t}$ method (Livak and Schmittgen, 2001).

Table 1

List of primers used for qRT-PCR of NLX-4 genes which were differentially expressed in transcriptome analysis.

\begin{tabular}{|c|c|c|}
\hline \multirow[t]{2}{*}{ Gene ID \&Description } & \multicolumn{2}{|l|}{ Sequence $5^{\prime}-3^{\prime}$} \\
\hline & Forward primer & Reverse primer \\
\hline NZ1GL005331 & AAGTTCCGCGTGTCCAACAC & TCAAAGCTCGAAGGCAGTGC \\
\hline \multicolumn{3}{|l|}{ Aminoacid-specific outer membrane pore } \\
\hline NZ1GL001246 & ATCAAAGCCACTGTGCCCCT & GTTGAACAGCGGACGCACTT \\
\hline \multicolumn{3}{|l|}{ Nitric oxide dioxygenase } \\
\hline NZ1GL001295 & CAGGTCAAGCTGGAGCAGGA & GGCTGTCGTTGATCACCACC \\
\hline \multicolumn{3}{|l|}{ Glutathione S-transferase } \\
\hline NZ1GL001417 & GCATCCTCTTCCTCGAAGGC & GTGCGTTCGATACGCAGGTC \\
\hline \multicolumn{3}{|l|}{ Bacterioferritin } \\
\hline NZ1GL001889 & GCATGTACCGATGGTGGAGC & TTGGCTACTCCGGACTGCAG \\
\hline \multicolumn{3}{|l|}{ Polysaccharide biosynthesis protein } \\
\hline 16S rRNA & AACCGCGAGGTGGAGCTAAT & GCGACATTCTGATTCGCGAT \\
\hline
\end{tabular}

\section{Statistical analysis}

All experiments were conducted in triplicates to obtain statistically significant results. One-way analysis of variance (ANOVA) and two independent samples t-test were carried out to quantify the significant differences between different conditions. Pearson correlation analysis was performed to assess the effects of different factors on rock dissolution and release of elements. Statistical analysis was accomplished using the IBM SPSS 22.0 and R 3.3 .0 software.

\section{Results And Discussion}

\section{Screening of the efficient strain}

To confirm the type of rock used for the efficient strain screening, we analyzed the composition of the selected rock samples. The results revealed the percentages of potassium feldspar, quartz, and mica in isolated rock samples were $52 \%, 36 \%$, and $10 \%$ by mass, respectively. The rock mineral sheers analysis showed that $\mathrm{SiO}_{2}, \mathrm{Al}_{2} \mathrm{O}_{3}$, and $\mathrm{K}_{2} \mathrm{O}$ accounted for $73.8 \%, 13.4 \%$, and $9.9 \%$ by mass respectively, which proved that the selected rock samples are silicate rocks.

Studies have proved the interaction between the IAA producing bacteria and plants has various applications to the plants ranging from pathogenesis to the phyto-stimulation (Spaepen et al., 2007). The siderophore secreted by bacteria has been proved has a variety of vital capacities (Crosa and Walsh, 2002). For example, it can inhibit the reproduction of pathogenic microorganisms causing plant diseases

Page 5/19 
(Sahu and Sindhu, 2011), chelate metal ions (Neilands, 1995), and promote mineral decomposition (Neubauer et al., 2002). Therefore, the rock-dissolving abilities of 22 different microbial isolates were considered for further studies which were evaluated for their ability to produce IAA and siderophore (Table S1). The highly efficient strains producing IAA more than $10 \mathrm{mg} \mathrm{L}^{-1}$ (Arancon et al., 2004$)$ and exhibiting strong siderophore productivity (+++) (A/Ar: 0-0.6) were considered for further studies (Hesse et al., 2017). Based on the IAA and siderophore producing abilities, ten bacterial strains $\mathrm{NLX}-1,3,4,7,12,14,17,18,19$ and 22 were further considered for the rock-dissolution experiments. The rock-dissolving capacity of a microbial strain is directly proportional to the concentration of silicon released from the rocks (in the form of $\mathrm{SiO}_{2}$ in the fermentation broth). The rock-dissolving ability was calculated by finding the difference between the experimental and control groups respectively (Fig. 1a). The NLX-4 strain exhibited the significant advantageous effect in the release of Si $(\mathrm{P}<0.001)$. It was reported that the Pseudomonas sp. strains were among these typical bacteria which produce both the IAA and siderophores (Bano and Musarrat, 2003; Gupta et al., 2002; Rajkumar et al., 2005). It also showed that the release of Si from rock by NLX-4 increased by $7.51 \mathrm{mg} \mathrm{L}^{-1}$ compared to control after $7 \mathrm{~d}$ of cultivation, which was remarkably higher than the amount of Si-releasing induced by reported Pseudomonas strains (Maurice et al., 2001). Thus we have selected NLX-4 strain for further genomic studies.

\section{Identification of silicate rock-dissolving strain NLX-4}

The standard morphological experiments of NLX-4 strain showed NLX-4 strain is a rod-shaped gram-negative bacterium with single flagella (Fig. S2a). To further identify the NLX-4 strain, sequenced 16S rRNA gene of NLX-4 strain was submitted to NCBI GenBank with an accession number KX379232 (Fig. S2b). Results obtained from BLAST and the phylogenetic tree analysis endorsed that NLX-4 strain belonged to the Pseudomonas genus (Fig. S2). Based on the results of the morphological and phylogenetic analysis, NLX-4 strain was identified as a Pseudomonas sp. strain.

\section{Effects of Pseudomonas sp. NLX-4 on rock-dissolution}

The final concentrations of $\mathrm{K}, \mathrm{Al}$, and Si released from silicate rock samples by $\mathrm{NLX}-4$ strain showed an increasing trend, while the particle diameter variation of rock samples increased significantly in 0 to 15 days cultures followed by a slight decline in the PDV values in the later time periods respectively (Fig. 1b). We have observed a gradual increase in release of elements from 2 nd to 30 th day cultures of NLX4 strain respectively (Fig. 1b). The concentrations of $\mathrm{K}, \mathrm{Al}$ and $\mathrm{Si}\left(\mathrm{mg} \mathrm{L}^{-1}\right)$ elements released by NLX-4 reached a maximum by the 30 th day with $73.27 \mathrm{mg} \mathrm{L}^{-1}, 62.43 \mathrm{mg} \mathrm{L}^{-1}$, and $26.50 \mathrm{mg} \mathrm{L}^{-1}$ respectively. The highest value of PDV was observed on 15 th day cultures of NLX$4(2.18 \mathrm{~mm})$, which later reduced to $1.60 \mathrm{~mm}$ by 30 th day respectively (Fig. $1 \mathrm{~b})$.

To explore the effective components of NLX-4 strain promoting the rock dissolution, we have analyzed and compared the final concentrations of exo-polysaccharides, amino acids, and organic acids secreted in fermentation broth (Table S2). Pearson analysis was used to assess the correlation between PDV, element concentrations, EPS, amino acids, and organic acids respectively (Fig. 1c). Apparently, PDV of rock samples has highly significant correlations ( $\mathrm{P}<0.001)$ with the release of $\mathrm{K}, \mathrm{Al}, \mathrm{Si}(\mathrm{Fig}$. $1 \mathrm{c})$. Meanwhile, EPS, amino acids, and all organic acids exhibited highly significant correlations $(P<0.001)$ with PDV, with malic acid being the most relevant factor (Fig. 1c). In addition, EPS, amino acids, tartaric acid, and malic acid showed highly significant correlations $(P<0.001)$ with the release of three elements (Fig. 1c). During the process of rock dissolution, the EPS and amino acids produced by bacterial strain were proven to have the capacity to destroy the crystal structure of rocks, which attains strength in the acidic environments (Braissant et al., 2003). The organic acids secreted by a bacterial strain not only create favorable acidic environmental conditions for the dissolution of the rock, but also have advantages over inorganic acids to dissolve rock due to their complexation with the cations in the mineral crystal lattice of rocks (Wu et al., 2017b; Wu et al., 2017c). In this study, the oxalic acid might show more complexation than acid solubilizing capacity to release K, Al, and $\mathrm{Si}$, while the other three acids had different degrees of complexation with these elements.

\section{Sequencing and assembly of NLX-4 strain}

The genome of NLX-4 strain was sequenced and de novo assembled by implementing a hybrid approach involving PacBio RSII and Illumina HiSeq 4000 sequencing systems. The quality control analysis on the raw read sequences has resulted in 713,706, 632 base pairs of clean sequence data and total of 79,379 sequences with a mean read length of 8,991bp (Table S4). Thus, obtained filtered subreads were further subjected to de novo assembly using RS_HGAP Assembly v3 in SMRT® analyser v2.3.0 software. The assembly of the PacBio sequence data was performed using the soapSNP and soaplndel by using the Illumina HiSeq 4000 sequence data.

The sheared genomic DNA of NLX-4 was also subjected to Illumina HiSeq 4000 sequencing system by constructing a 300 bp insert library with $2 \times 100$ bp read length. The Illumina sequencing has resulted in $904 \mathrm{Mb}$ of raw data with an adapter and duplication percentages to be 0.23 and 8.03 respectively and total reads were 9,049,948 (Table 2 and S4). The quality control analysis has resulted in clean data of $817 \mathrm{Mb}$ of sequence data with filtered reads and low-quality filtered reads percentages were 9.68 and 1.39 respectively (Table 2 and S4).

Page 6/19 
The final NLX-4 genome sequence assembly resulted in single chromosome with 0 gaps, single base quality of 1 , structure base and reads usage percentages were 0.9975 and 0.9915 respectively at a genome depth of 40.75 and genome size of $6.52 \mathrm{Mb}$ (Table S5a). The gene prediction of the NLX-4 genome sequence was performed using the Glimmer v3.0.2 and the whole genome sequence was analyzed for the annotations using BLAST with non-redundant protein database (NR), Swiss-Prot, TrEMBL, COG, KEGG, InterPro and GO databases. The genome was also analyzed using the following servers RNAmmer, tRNAscan, Rfam, IslandPath-DIOM, SIGI-HMM, IslandPickerp and CRISPR Finder servers respectively (Fig. S3-S5).

Table 2

Summary of sequences analysis of genome

\begin{tabular}{|ll|}
\hline Description & Number \\
\hline Insert Size (bp) & 300 \\
\hline Reads Length (bp) & $(100: 100)$ \\
\hline Raw Data (Mb) & 904 \\
\hline Adapter (\%) & 0.23 \\
\hline Duplication (\%) & 8.03 \\
\hline Total Reads & $9,049,948$ \\
\hline Filtered Reads (\%) & 9.68 \\
\hline Low Quality Filtered Reads (\%) & 1.39 \\
\hline Clean Data (Mb) & 817 \\
\hline After Assembly & \\
\hline Genome Size & $6,771,445$ \\
\hline GC (\%) & 63.21 \\
\hline Repeat Number & 1,049 \\
\hline Repeat Length & 130,540 \\
\hline Min Length & 25 \\
\hline Max Length & 5,847 \\
\hline Average Length & 124.44 \\
\hline Repeat Rate & 1.93 \\
\hline
\end{tabular}

The genome of Pseudomonas NLX-4 strain is a single circular chromosome with $6.7 \mathrm{Mb}(6,771,445 \mathrm{bp})$ length and $63.21 \%$ of $\mathrm{G}+\mathrm{C}$ content (Table 2). The genome contains 6,239 protein coding genes with an average length; internal length and internal GC content were $949 \mathrm{bp}$, $852,628 \mathrm{bp}$ and $56.55 \%$ respectively (Table S5b). It also contains 72 tRNA genes, 19 rRNA genes and 17 sRNA genes. The NLX-4 genome has also showed sequencers for an intact prophage sequence with a length of 39233 bp (start: 5375574 , end: 5414806 ) with a GC\% of 61.36. The results from Tandem Repeat Finder software shows that the genome contains a total of 192 tandem repeat fragments (TRF), 90 minisatellite and 36 microsatellite DNA sequences with total lengths of 35,083bp, 4,597bp and 1380bp respectively (Table S5d). Total of four CRISPR (ID-1, 2, 3 and 4) spacer sequences with a sequence length ranging between 34, 3540 and 48 respectively and gene Island analysis has resulted in 54 gene islands (Table S5e).

To benefit the further study on microbial weathering, a whole genomic sequencing was also conducted in our research. The whole genome was annotated using BLAST annotation pipeline by searching and retrieving the genome wide annotations from different annotation databases such as prokaryotic orthologous groups (COG), gene ontology (GO), InterPro, KEGG, BLAST-NR, Swiss-Prot databases, respectively. The annotated genome of NLX-4 strain contains a total of 6041 (96.82\%) protein coding gene sequences, with 5045 (80.86\%) COG, 3996 (64.04\%) GO, 5342 (85.62\%) InterPro, 4386 (70.29\%) KEGG, 6038 (96.77\%) BLAST-NR and 3897 (62.46\%) Swiss-Prot respectively (Table S5f). The COG has classified the protein encoding genes into $25 \%$-cellular signaling and processing, $17 \%$-information storage and processing, 42\%-metabolism and 16\%-poorly characterized respectively (Fig. 2). The GO has classified protein coding genes into $55 \%$-biological process, $16 \%$-cellular process and $29 \%$-molecular function respectively (Fig. 3). The KEGG database has divided protein coding genes into $52 \%$-metabolism, $6 \%$-organismal systems, $5 \%$-cellular processes, $14 \%$-environmental information processing, 
10\%-genetic information and processing and 13\%-human diseases respectively (Fig. 3). Genes encoding for transcription regulator HTH (LysR), ABC transporter like, Signal transduction response regulator ABC transporter (Metl-like), GCN5-N-acetyltransferase (GNAT), PAS domain, Major facilitator superfamily, Homeodomain-like, Histidine kinase, Short-chain dehydrogenase, DNA-binding HTH, EamA domain, TonB dependent receptor proteins and other genes were found to occur in multiple copies in the NLX-4 genome (Fig. 2).

\section{Rock-dissolution molecular mechanisms and genes}

In NLX-4 genome, 2124 genes exhibit catalytic activity, 29 genes exhibit antioxidant activity, 1595 genes exhibit binding activity (Fig. 3). Genome of NLX-4 encodes genes involved in important metabolic pathways with 819- amino acid metabolism pathways, 83-biosynthesis of secondary metabolites, 732-carbohydrate metabolism, 399-energy metabolism, 270-glycan biosynthesis and metabolism, 161metabolism of other amino acids, 194-metabolism of terpenoids and polyketides, 480-xenobiotic biodegradation and metabolism respectively. The prokaryotic orthologous group classification of NLX-4 genome contains 311 genes in energy production and conversion, 642-amino acid transport and metabolism, 315-carbohydrate transport and metabolism, 183-secondary metabolite biosynthesis, transport and metabolism respectively (Fig. 3). Metabolically, some of the important genes include siderophore encoding genes (NZ1GL004767; NZ1GL000887; NZ1GL005349), polysaccharide biosynthesis protein (NZ1GL001889), nitric oxide dioxygenase (NZ1GL001246) and other proteins which are involved in the biosynthesis of organic acids, amino acids and secondary metabolites required for the dissolution of rocky material.

\section{Transcriptome of NLX-4}

The sequencing has resulted in a total of 143 million reads with each sample the number of reads varied between 23 to 24 million reads respectively (Table 3a and b). The quality control analysis was performed to discard the low-quality reads and obtain clean reads; these clean reads were further mapped both to the gene and genome of NLX-4 strain obtained above. The RNA sequence data of six samples (control and treatment (NLX-4) in triplicates) were aligned to the reference genome using SOAPv2.0. The sequence reads were aligned to the NLX-4 genome and non-ribosomal reads which did not align uniquely with the NLX-4 genomic sequences were removed. Total number of rRNA reads mapped to the NLX-4 reference genome varied from $0.10-1.51 \%$ respectively. The alignment results obtained from gene and genome level were reported in Table $3 a$ and b respectively. On average $90.53 \%$ of transcripts were found to be mapped to the genome of NLX-4, which demonstrates the suitability of using RNA sequencing data for further studies. 
Table 3

a) Summary of mapping to genes; b) Summary of mapping to genomes

\begin{tabular}{|c|c|c|c|c|c|c|c|c|c|}
\hline \multicolumn{10}{|l|}{ a. Gene } \\
\hline Sample & & $\begin{array}{l}\text { Total } \\
\text { reads }\end{array}$ & $\begin{array}{l}\text { Total base } \\
\text { pairs }\end{array}$ & $\begin{array}{l}\text { Total } \\
\text { mapped } \\
\text { reads }\end{array}$ & $\begin{array}{l}\text { Perfect } \\
\text { match }\end{array}$ & $\begin{array}{l}<=5 b p \\
\text { mismatch }\end{array}$ & $\begin{array}{l}\text { Unique } \\
\text { match }\end{array}$ & $\begin{array}{l}\text { Multi- } \\
\text { position } \\
\text { match }\end{array}$ & $\begin{array}{l}\text { Total } \\
\text { unmapped } \\
\text { reads }\end{array}$ \\
\hline \multirow[t]{2}{*}{$\begin{array}{l}\text { Treatment } \\
1\end{array}$} & $\begin{array}{l}\text { reads } \\
\text { number }\end{array}$ & 24990982 & 2499098200 & 10697962 & 6828765 & 3869197 & 10642255 & 55707 & 14293020 \\
\hline & percentage & $100.00 \%$ & $100.00 \%$ & $42.81 \%$ & $27.32 \%$ & $15.48 \%$ & $42.58 \%$ & $0.22 \%$ & $57.19 \%$ \\
\hline \multirow[t]{2}{*}{$\begin{array}{l}\text { Treatment } \\
2\end{array}$} & $\begin{array}{l}\text { reads } \\
\text { number }\end{array}$ & 24662260 & 2466226000 & 6015324 & 3855412 & 2159912 & 5968251 & 47073 & 18646936 \\
\hline & percentage & $100.00 \%$ & $100.00 \%$ & $24.39 \%$ & $15.63 \%$ & $8.76 \%$ & $24.20 \%$ & $0.19 \%$ & $75.61 \%$ \\
\hline \multirow[t]{2}{*}{$\begin{array}{l}\text { Treatment } \\
3\end{array}$} & $\begin{array}{l}\text { reads } \\
\text { number }\end{array}$ & 23053138 & 2305313800 & 4651007 & 2865703 & 1785304 & 4616782 & 34225 & 18402131 \\
\hline & percentage & $100.00 \%$ & $100.00 \%$ & $20.18 \%$ & $12.43 \%$ & $7.74 \%$ & $20.03 \%$ & $0.15 \%$ & $79.82 \%$ \\
\hline \multirow[t]{2}{*}{ CK 1} & $\begin{array}{l}\text { reads } \\
\text { number }\end{array}$ & 23478916 & 2347891600 & 9928596 & 6315556 & 3613040 & 9883855 & 44741 & 13550320 \\
\hline & percentage & $100.00 \%$ & $100.00 \%$ & $42.29 \%$ & $26.90 \%$ & $15.39 \%$ & $42.10 \%$ & $0.19 \%$ & $57.71 \%$ \\
\hline \multirow[t]{2}{*}{ CK 2} & $\begin{array}{l}\text { reads } \\
\text { number }\end{array}$ & 23681178 & 2368117800 & 8357772 & 5383694 & 2974078 & 8323882 & 33890 & 15323406 \\
\hline & percentage & $100.00 \%$ & $100.00 \%$ & $35.29 \%$ & $22.73 \%$ & $12.56 \%$ & $35.15 \%$ & $0.14 \%$ & $64.71 \%$ \\
\hline \multirow[t]{2}{*}{ CK 3} & $\begin{array}{l}\text { reads } \\
\text { number }\end{array}$ & 23458688 & 2345868800 & 9011855 & 5664846 & 3347009 & 8970619 & 41236 & 14446833 \\
\hline & percentage & $100.00 \%$ & $100.00 \%$ & $38.42 \%$ & $24.15 \%$ & $14.27 \%$ & $38.24 \%$ & $0.18 \%$ & $61.58 \%$ \\
\hline
\end{tabular}

\begin{tabular}{|c|c|c|c|c|c|c|c|c|c|}
\hline \multicolumn{10}{|l|}{ b. Genome } \\
\hline Sample & & $\begin{array}{l}\text { Total } \\
\text { reads }\end{array}$ & $\begin{array}{l}\text { Total base } \\
\text { pairs }\end{array}$ & $\begin{array}{l}\text { Total } \\
\text { mapped } \\
\text { reads }\end{array}$ & $\begin{array}{l}\text { Perfect } \\
\text { match }\end{array}$ & $\begin{array}{l}<=5 b p \\
\text { mismatch }\end{array}$ & $\begin{array}{l}\text { Unique } \\
\text { match }\end{array}$ & $\begin{array}{l}\text { Multi- } \\
\text { position } \\
\text { match }\end{array}$ & $\begin{array}{l}\text { Total } \\
\text { unmapped } \\
\text { reads }\end{array}$ \\
\hline \multirow[t]{2}{*}{$\begin{array}{l}\text { Treatment } \\
1\end{array}$} & $\begin{array}{l}\text { reads } \\
\text { number }\end{array}$ & 24990982 & 2499098200 & 24344932 & 15806518 & 8538414 & 24228961 & 115971 & 646050 \\
\hline & percentage & $100.00 \%$ & $100.00 \%$ & $97.41 \%$ & $63.25 \%$ & $34.17 \%$ & $96.95 \%$ & $0.46 \%$ & $2.59 \%$ \\
\hline \multirow[t]{2}{*}{$\begin{array}{l}\text { Treatment } \\
2\end{array}$} & $\begin{array}{l}\text { reads } \\
\text { number }\end{array}$ & 24662260 & 2466226000 & 22413096 & 14736337 & 7676759 & 22119377 & 293719 & 2249164 \\
\hline & percentage & $100.00 \%$ & $100.00 \%$ & $90.88 \%$ & $59.75 \%$ & $31.13 \%$ & $89.69 \%$ & $1.19 \%$ & $9.12 \%$ \\
\hline \multirow[t]{2}{*}{$\begin{array}{l}\text { Treatment } \\
3\end{array}$} & $\begin{array}{l}\text { reads } \\
\text { number }\end{array}$ & 23053138 & 2305313800 & 20972730 & 13202897 & 7769833 & 20856681 & 116049 & 2080408 \\
\hline & percentage & $100.00 \%$ & $100.00 \%$ & $90.98 \%$ & $57.27 \%$ & $33.70 \%$ & $90.47 \%$ & $0.50 \%$ & $9.02 \%$ \\
\hline \multirow[t]{2}{*}{ CK 1} & $\begin{array}{l}\text { reads } \\
\text { number }\end{array}$ & 23478916 & 2347891600 & 22549111 & 14560281 & 7988830 & 22189053 & 360058 & 929805 \\
\hline & percentage & $100.00 \%$ & $100.00 \%$ & $96.04 \%$ & $62.01 \%$ & $34.03 \%$ & $94.51 \%$ & $1.53 \%$ & $3.96 \%$ \\
\hline
\end{tabular}

We have observed that in control samples the total number of rRNA reads count were slightly higher than the treatment samples, which might be due to the insignificantly higher rRNA to mRNA ratios in control samples. The present genome wide transcriptome study of NLX-4 completely covered the majority of all the genes with more than one read. Higher reproducibility was observed among the biological replicates, they have similar number of total and the mapped reads (Fig. S11-S13). The mapped reads were further subjected to a series of analysis including sequence assessment, biological contextualization, gene structure refinement, alternative splicing, novel transcript detection and SNP analysis (Fig. S14). Transcriptome analysis conducted by edgeR, limma and Glimma packages showed that the strain 
NLX-4 cultured with/without silicate rocks resulted in 539 (288-up and 251-down) DEGs. Those DEGs were further analyzed for its biological contextualization using GO and KEGG pathway enrichment analysis (Fig. S15).

\section{Differentially expressed genes}

As the bacteria were previously reported to release nutrients from rocks for their growth (Alahari and Apte, 2004), the rocks using as a kind of nutritional source were considered to have its influence on the metabolic process of bacteria (Xiao et al., 2012a). Compared to the samples composed of soluble $\mathrm{K}(\mathrm{KCl})$ as potassium source, the NLX-4 strain using K-bearing silicate rock as potassium source has resulted in higher EPS, amino acids, and organic acids. These differences illustrated that the interaction of NLX-4 strain and rock to release nutrients for bacterial growth significantly accelerated the process of rock dissolution (Wu et al., 2017c). The RPKM values obtained from the quantification of the control and treatment samples were used for finding the significant DEG. We have followed two different approaches for finding the DEGs among the samples a) using the Audic Claverie method b) using a customized pipeline implementing edgeR, limma and Glimma packages. The results obtained from both the approaches have given us almost the same list of DEGs. Genes encoding for nitric oxide dioxygenase, flagellin, glutathione-S-transferase (GST), chaperonin GroES, heat shock protein HSP10, elongation factor prokaryotic, bacterioferritin, polysaccharide biosynthesis protein Epsc, DNA-methyl transferase, flagellar FliS, FlaG, FlgN protein, diguanylate cyclase, large ribosomal protein L7 and two component system-NARXL were highly expressed with a fold change values log > 2.5 (Fig. 4 and S15). While the genes encoding for fatty acyl-CoA synthase, sulfur dioxygenase, DNA polymerase III, acetyltransferase, cation symporter, sulfide: quinone oxidoreductase, alcohol dehydrogenase, pyrroloquinoline quinone biosynthesis protein $B$, hydrogen cyanide synthase $(\mathrm{HcnB}), \mathrm{CBS}$ domain, cytochrome c peroxidase, polar amino acid transport system, cytochrome $\mathrm{c}$ oxidase and nitrate reductases were down regulated in the treatment samples with a fold change value of log <2.5 respectively (Fig. 4 and S15). We have also analyzed the enrichment of the DEGs in biological pathways using KEGG pathways and GO analysis respectively (Fig. 4 and S15). RTqPCR was used to further validate the expression level of genes identified in Illumina sequencing analysis. A total of 5 DEGs, encoding for basic amino acid, nitric oxide dioxygenase, GST, bacterioferritin, and polysaccharide biosynthesis protein, with relatively higher gene expressions were chosen as candidates for the RT-qPCR study (Table 1). These 5 DEGs showed a consistent pattern between Illumina sequencing results and RT-qPCR (Fig. S17), which indicated that the transcriptome data are reliable and accurate.

As has been already known, a total of 15 genes involved in the regulations of ironophore transportation, EPS and amino acids synthesis, and organic acids metabolism were highly expressed with a fold change values log $>2.5$. The bacterioferritin encoding gene (involved in ironophore and transportation of siderophore) (Carrondo, 2003), was highly up-regulated in the tested conditions.

The gene ontology analysis of the DEGs showed that majority of these gene products are mainly involved in the process of protein translation, metabolic, and cellular macromolecule biosynthesis (Fig. 4). This study also proposes the involvement of EPS, amino acids and organic acid are associated with various factors playing crucial roles in protein translation, metabolic, and cellular macromolecule biosynthetic, such as elongation factors and large ribosomal protein L7 processes. In addition, the oxidoreductases such as nitric oxide dioxygenase were also found to regulate the amino acids and organic acid metabolism reactions (Litvinova et al., 2015). The up-regulation of genes involved in macromolecular assembly of extracellular proteins, polysaccharides, and glycoproteins, might be involved in creating a better weathering microenvironment during a) bacterial attachment to rock particles, b) formation of the bacterial-rock aggregates. Genes encoding for flagellin, polysaccharide biosynthesis protein Epsc, flagellar FliS, FlaG, FlgN protein, diguanylate cyclase (Chen and Schaap, 2012) endorses the above functions. The gene encoding for DNA-methyl transferase with a function inducing the lipopolysaccharide, was found to be highly up-regulated (Zhang et al., 2013) and these results also confirms the existence of polysaccharides in the environment (Fig. 4).

Glutathione (GSH) is essential for the cells to adapt to the deficiency of $\mathrm{K}^{+}$deficiency by acting as an important antioxidant and detoxifying agent in cells (Wang et al., 2015). GST has the function to catalyze the conjugation of glutathione with a wide variety of electrophiles (Beckett and Hayes, 1993). In the process of rock dissolving, various elements in the crystal lattice of rocks are released. Apart from cell biogenic elements, some heavy metal elements and impurities also enter into the bacterial cells as exogenous substances, which generate toxic effects such as inducing oxidative stress (Sun et al., 2013). Therefore, Pseudomonas sp. NLX-4 performs cell detoxification by up-regulating the expression of GST genes, and homeostasis in its cells can be maintained to overcome the harsh environment. GST has been found up-regulated in the bio-dissolving of K-bearing mineral affected by Aspergillus fumigatus (Xiao et al., 2012b), which is consistent with the results of this study. Furthermore, two component system-NARXL in bacteria, which referred to numerous sensory-response circuits operate by making use of a phosphorylation control mechanism (Kobayashi et al., 2016), is also helpful for bacteria to be masters at adapting and coordinating cellular events to accommodate adverse conditions.

Moreover, as $\mathrm{K}^{+}$is an essential element for the metabolism of bacteria because of its indispensability for synthesis of proteins and enzymes, Pseudomonas sp. NLX-4 may first cause incorrect folding of proteins and enzymes without $\mathrm{K}^{+}$. Therefore, amounts of mis-/un-

Page $10 / 19$ 
folded proteins will accumulate in the cell. In the case of $\mathrm{K}^{+}$deficiency, Pseudomonas sp. NLX-4 launched a stress response to up-regulate expression of chaperonin (GroES) and heat shock protein (HSP10), which played an important role in protein folding.

\section{Global expression of novel transcripts and sRNA}

The novel transcripts expressed differentially among the control and treatment samples were also analyzed using the customized pipeline using edgeR, limma and Glimma packages. The RNA sequencing has resulted in total of 9681(CK-1), 9931 (CK-2), 9424 (CK-3), 10010 (Treatment-1), 11470 (Treatment-2) and 11695 (Treatment-3) transcripts, respectively. Out of which, 208, 229, 215, 186, 222 and 230 novel transcripts encoded for the coding regions and 9473, 9702, 9209, 9824, 11248 and 11465 novel transcripts encoded for the non-coding regions respectively (Fig. S18). Results obtained from the differential expression results have showed that a total of 847 novel transcript encoding genes were highly up regulated with $\geq 2$.0-fold change values and 169 novel transcript encoding genes were down regulated with $\leq 2.0$-fold change values respectively. Novel transcripts encoding for succinate dehydrogenase/fumarate reductase (TU1181), uncharacterized MFS-type transporter YbfB (TU1209), DNAJ domain (TU1447) were highly up-regulated and transcripts encoding for domain of unknown function (TU263), GGDEF domain (TU882), glucose-6-phosphate dehydrogenase (TU798), aldo/keto reductase (TU209), P-loop nucleoside triphosphate hydrolase (TU427), polyhydroxyalkanoic acid protein system (TU1525), HTH ArsR type DNA binding domain (TU955), thioesterase (TU1556), cytidine and deoxycytidylate deaminase (TU331), ABC type transporter (TU1129), metal sensitive transcriptional repressor (TU957), DNA polymerase (TU967), acyl-CoA dehydrogenase (TU1534), GNAT domain (TU315), alcohol dehydrogenase (TU1632), MarR type HTH domain (TU710) and WD40 repeat (TU879) transcripts were down-regulated.

In the analysis of novel transcripts, succinate dehydrogenase is found out as one of the key enzymes in the pathway tricarboxylic acid cycle, which is part of carbohydrate metabolism (Araujo et al., 2012), and catalyzes the reaction of succinic acid converting to tartaric acid (Pan et al., 2010). Uncharacterized MFS-type transporter YbfB is involved in the transmembrane transport (Aminov et al., 2002), which is related to the secretion of bacterial secondary metabolites (ironophore, EPS, amino acids, and organic acids, et al.). DNAJ domain is involved in protein folding in the cell by acting as a co-molecular chaperone under environmental stresses (Bascos, 2008). Therefore, combining with the analysis results of novel transcripts indicating the genes encoding succinate dehydrogenase/fumarate reductase (TU1181), uncharacterized MFS-type transporter YbfB (TU1209), DNAJ domain (TU1447) were highly up up-regulated, our opinion is that the essential elements bacteria need caused rock microbial-dissolving and the EPS, amino acids, organic acids secreted by bacterial strain accelerate rock dissolving were further confirmed.

Overall, a major disadvantage in current external-soil spray seeding technology is that the soil substrates used in these eco-restoration technologies showed poor rock interface fusion. Our present study displays a great potential to overcome these disadvantages by employing multifunctional bacteria such as Pseudomonas sp. NLX-4 strain to improve the interactions between the soil substrates and rock samples. Moreover, our study lays a firm foundation to further explore the deeper molecular mechanisms of rock dissolution by identifying the DEGs involved in this process.

\section{Limitations of the study}

Although we have isolated and screened out the efficient bacterium Pseudomonas sp. NLX-4 that can be applied for improving the current external-soil spray seeding technology, all experiments were completed under the optimal experimental conditions. Therefore, a field experiment combining Pseudomonas sp. NLX-4 with external-soil spray seeding technology should be conducted to verify the effect of this strain in the natural environment of the rock mining site. Furthermore, proteome sequencing will be a valuable tool to further research and explain the relationship between genes, pathways, proteins and metabolites, so that the molecular mechanisms could be fully revealed. In any case, the role of Pseudomonas sp. NLX-4 and its selected genetic resources in the improvement of external-soil spray seeding technology is worth expecting.

\section{Declarations}

Supplementary Information: The supplementary information contains tables and figures.

\section{Ethics approval and consent to participate}

No applicable

\section{Consent for publication}

Authors agreed to publish this article. 
Availability of Data and Materials: Full genomic and transcriptomic datasets of Pseudomonas sp. NLX-4 are available at National Center for Biotechnology Information (NCBI) https://www.ncbi.nlm.nih.gov/geo/query/acc.cgi?acc=GSE155316 with the GEO accession number GSE155316. This study did not generate new unique reagents.

\section{Competing Interests}

The authors have declared that no competing interest exists.

\section{Funding}

This work was supported by the National Special Fund for Forestry Scientific Research in the Public Interest of China (Grant No. 201504406), Jiangsu Agriculture Science and Technology Innovation Fund (Grant No. CX (17) 1004), and Priority Academic Program Development of Jiangsu Higher Education Institutions (PAPD) to J. Z., Canada Ontario Research Chair Funding to W. Q., and Ontario Trillium Scholarship to AKSK.

\section{Author contributions}

Conceptualization, Y.W. and J.Z.; Methodology, Y.W., B.Z. and F.C.; Investigation, Y.W., F.C. and M.M.; Writing - Original Draft, Y.W. and AKSK; Writing - Review \& Editing, W.Q., J.Z., Y.W. and AKSK; Funding Acquisition, J.Z., W.Q. and AKSK; Resources, J.Z.; Supervision, J.Z. and W.Q.

Acknowledgements: Not applicable

\section{Author's details}

${ }^{1}$ Co-innovation Center for Sustainable Forestry in Southern China, Jiangsu Province Key Laboratory of Soil and Water Conservation and Ecological Restoration, Nanjing Forestry University, 159 Longpan Road, Nanjing, Jiangsu 210037, China.

2 Department of Biology, Lakehead University, 955 Oliver Road, Thunder Bay, Ontario, P7B 5E1, Canada.

${ }^{3}$ Department of Biology, University of Miami, Coral Gables, FL 33124, USA.

${ }^{4}$ Co-innovation Center for Sustainable Forestry in Southern China, Jiangsu Province Key Laboratory for Prevention and Management of Invasive Species, Nanjing Forestry University, 159 Longpan Road, Nanjing, Jiangsu 210037, China.

${ }^{5}$ Learning Support Team, St Margaret's School, Victoria, BC, V8X 3P7, Canada (current address)

Lead contact: Further information and requests for resources and reagents should be directed to and will be fulfilled by the Lead contact, Dr. Jinchi Zhang (zhang8811@njfu.edu.cn).

\section{References}

Alahari, A. and Apte, S.K., 2004. A novel potassium deficiency-induced stimulon in Anabaena torulosa. Journal of Biosciences, 29(2): 153162.

Aminov, R.I. et al., 2002. Development, Validation, and Application of PCR Primers for Detection of Tetracycline Efflux Genes of GramNegative Bacteria. Applied \& Environmental Microbiology, 68(4): 1786.

Arancon, N.Q., Edwards, C.A., Atiyeh, R. and Metzger, J.D., 2004. Effects of vermicomposts produced from food waste on the growth and yields of greenhouse peppers. Bioresource Technology, 93(2): 139-144.

Araujo, W.L., NUNES-NESI, A., Nikoloski, Z., Sweetlove, L.J. and Fernie, A.R., 2012. Metabolic control and regulation of the tricarboxylic acid cycle in photosynthetic and heterotrophic plant tissues. Plant, cell \& environment, 35(1): 1-21.

Audic, S. and Claverie, J.-M., 1997. The significance of digital gene expression profiles. Genome research, 7(10): 986-995.

Balland-Bolou-Bi, C. and Poszwa, A., 2012. Effect of calco-magnesian amendment on the mineral weathering abilities of bacterial communities in acidic and silicate-rich soils. Soil Biology and Biochemistry, 50: 108-117.

Page $12 / 19$ 
Bano, N. and Musarrat, J., 2003. Characterization of a new Pseudomonas aeruginosa strain NJ-15 as a potential biocontrol agent. Current microbiology, 46(5): 0324-0328.

Bascos, N.A., 2008. The requirement of J-domain structural rigidity for cochaperone-mediated allostery in the DnaJ-DnaK molecular chaperone machine. Dissertations \& Theses - Gradworks.

Beckett, G.J. and Hayes, J.D., 1993. Glutathione S-transferases: biomedical applications. Advances in Clinical Chemistry, 30(1): 281-380.

Boetzer, M. and Pirovano, W., 2014. SSPACE-LongRead: scaffolding bacterial draft genomes using long read sequence information. BMC bioinformatics, 15(1): 211.

Bouwer, E.J. and Zehnder, A.J., 1993. Bioremediation of organic compounds-putting microbial metabolism to work. Trends in biotechnology, 11(8): 360-367.

Braissant, O., Cailleau, G., Dupraz, C. and Verrecchia, E.P., 2003. Bacterially induced mineralization of calcium carbonate in terrestrial environments: the role of exopolysaccharides and amino acids. Journal of Sedimentary Research, 73(3): 485-490.

Bric, J.M., Bostock, R.M. and Silverstone, S.E., 1991. Rapid in situ assay for indoleacetic acid production by bacteria immobilized on a nitrocellulose membrane. Applied and environmental Microbiology, 57(2): 535-538.

Carrondo, M.A., 2003. Ferritins, iron uptake and storage from the bacterioferritin viewpoint. Embo Journal, 22(9): 1959-1968.

Chen, S., Lian, B. and Liu, C., 2008. Effect of Bacillus mucilaginosus on weathering of phosphorite and a preliminary analysis of bacterial proteins. Chinese Journal of Geochemistry, 27(2): 209-216.

Chen, Z.H. and Schaap, P., 2012. The prokaryote messenger c-di-GMP triggers stalk cell differentiation in Dictyostelium. Nature, 488(7413): 680-683.

Comino, J.R. et al., 2016. Quantitative comparison of initial soil erosion processes and runoff generation in Spanish and German vineyards. Science of the Total Environment, 565: 1165-1174.

Crosa, J.H. and Walsh, C.T., 2002. Genetics and assembly line enzymology of siderophore biosynthesis in bacteria. Microbiology and molecular biology reviews, 66(2): 223-249.

Erkossa, T., Wudneh, A., Desalegn, B. and Taye, G., 2015. Linking soil erosion to on-site financial cost: lessons from watersheds in the Blue Nile basin. Solid Earth, 6(2): 765.

Finlay, R. et al., 2009. The role of fungi in biogenic weathering in boreal forest soils. Fungal Biology Reviews, 23(4): 101-106.

Gleeson, D.B. et al., 2006. Characterization of bacterial community structure on a weathered pegmatitic granite. Microbial Ecology, 51(4): 526-534.

Gómez-Lozano, M., Marvig, R.L., Molin, S. and Long, K.S., 2012. Genome-wide identification of novel small RNAs in Pseudomonas aeruginosa. Environmental microbiology, 14(8): 2006-2016.

Gupta, A., Meyer, J.M. and Goel, R., 2002. Development of heavy metal-resistant mutants of phosphate solubilizing Pseudomonas sp. NBRI 4014 and their characterization. Current microbiology, 45(5): 323-327.

Hesse, E. et al., 2017. Ecological selection of siderophore-producing microbial taxa in response to heavy metal contamination. bioRxiv: 163774.

Jeffries, P., Gianinazzi, S., Perotto, S., Turnau, K. and Barea, J.-M., 2003. The contribution of arbuscular mycorrhizal fungi in sustainable maintenance of plant health and soil fertility. Biology and fertility of soils, 37(1): 1-16.

Jiang, H., Song, W., Li, A., Yang, X. and Sun, D., 2011. Identification of genes differentially expressed in cauliflower associated with resistance to Xanthomonas campestris pv. campestris. Molecular biology reports, 38(1): 621-629.

Kanicky, V. and Mermet, J.-M., 1997. Selection of internal standards for the determination of major and minor elements in silicate rocks and limestones by laser ablation inductively coupled plasma atomic emission spectrometry. Applied spectroscopy, 51(3): $332-336$.

Page 13/19 
Kawahara, Y. et al., 2012. Simultaneous RNA-seq analysis of a mixed transcriptome of rice and blast fungus interaction. PloS one, 7(11): e49423.

Kobayashi, K. et al., 2016. Single-cell memory regulates a neural circuit for sensory behavior. Cell reports, 14(1): 11-21.

Li, R. et al., 2009. SOAP2: an improved ultrafast tool for short read alignment. Bioinformatics, 25(15): 1966-1967.

Li, R. et al., 2010. De novo assembly of human genomes with massively parallel short read sequencing. Genome research, $20(2): 265-272$.

Lian, B., Wang, B., Pan, M., Liu, C. and Teng, H.H., 2008. Microbial release of potassium from K-bearing minerals by thermophilic fungus Aspergillus fumigatus. Geochimica et Cosmochimica Acta, 72(1): 87-98.

Litvinova, L. et al., 2015. Nitric oxide and mitochondria in metabolic syndrome. Frontiers in Physiology, 6: 20.

Livak, K.J. and Schmittgen, T.D., 2001. Analysis of relative gene expression data using real-time quantitative PCR and the $2-\Delta \triangle C T$ method. methods, 25(4): 402-408.

Maurice, P.A., Vierkorn, M.A., Hersman, L.E., Fulghum, J.E. and Ferryman, A., 2001. Enhancement of kaolinite dissolution by an aerobic Pseudomonas mendocina bacterium. Geomicrobiology Journal, 18(1): 21-35.

Meyer, M.L. and Bloom, P.R., 1993. Lithium metaborate fusion for silicon, calcium, magnesium, and potassium analysis of wild rice. Plant and soil, 153(2): 281-285.

Mortazavi, A., Williams, B.A., McCue, K., Schaeffer, L. and Wold, B., 2008. Mapping and quantifying mammalian transcriptomes by RNASeq. Nature methods, 5(7): 621-628.

Neilands, J., 1995. Siderophores: structure and function of microbial iron transport compounds. Journal of Biological Chemistry, 270(45): 26723-26726.

Neubauer, U., Furrer, G. and Schulin, R., 2002. Heavy metal sorption on soil minerals affected by the siderophore desferrioxamine B: the role of Fe (III)(hydr) oxides and dissolved Fe (III). European journal of soil science, 53(1): 45-55.

Ochoa-Cueva, P., Fries, A., Montesinos, P., Rodríguez-Díaz, J.A. and Boll, J., 2015. Spatial estimation of soil erosion risk by land-cover change in the Andes of Southern Ecuador. Land degradation \& development, 26(6): 565-573.

Pan, H., Bao, W., Xie, Z., Zhang, J. and Li, Y., 2010. Immobilization of -epoxysuccinate hydrolase activity for d(?)-tartaric acid production. Biotechnology Letters, 32(2): 235-241.

Prothero, D.R. and Schwab, F., 2004. Sedimentary geology. Macmillan.

Rajkumar, M., Nagendran, R., Lee, K.J. and Lee, W.H., 2005. Characterization of a novel Cr6+ reducing Pseudomonas sp. with plant growth-promoting potential. Current Microbiology, 50(5): 266-271.

Russell, J.E., 2002. Soil conditions and plants growth. Daya Books.

Sahu, G. and Sindhu, S., 2011. Disease control and plant growth promotion of green gram by siderophore producing Pseudomonas sp. Research Journal of Microbiology, 6(10): 735.

Sambrook, J. and Russell, D.W., 2006. Standard ethanol precipitation of DNA in microcentrifuge tubes. Cold Spring Harbor Protocols, 2006(1): pdb. prot4456.

Slater, G.S.C. and Birney, E., 2005. Automated generation of heuristics for biological sequence comparison. BMC bioinformatics, 6(1): 31.

Sohpal, V.K., Dey, A. and Singh, A., 2010. MEGA biocentric software for sequence and phylogenetic analysis: a review. International journal of bioinformatics research and applications, 6(3): 230-240.

Spaepen, S., Vanderleyden, J. and Remans, R., 2007. Indole-3-acetic acid in microbial and microorganism-plant signaling. FEMS microbiology reviews, 31(4): 425-448. 
Sun, L.L. et al., 2013. Differences in the gene expressive quantities of carbonic anhydrase and cysteine synthase in the weathering of

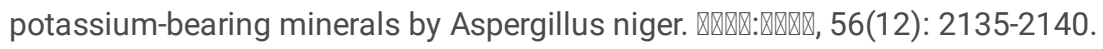

Tribelli, P.M. et al., 2015. Novel essential role of ethanol oxidation genes at low temperature revealed by transcriptome analysis in the antarctic bacterium Pseudomonas extremaustralis. PloS one, 10(12): e0145353.

Vandevivere, P., Welch, S., Ullman, W. and Kirchman, D., 1994. Enhanced dissolution of silicate minerals by bacteria at near-neutral pH. Microbial ecology, 27(3): 241-251.

Wang, W., Lian, B. and Pan, L., 2015. An RNA-sequencing study of the genes and metabolic pathways involved in Aspergillus niger weathering of potassium feldspar. Geomicrobiology Journal, 32(8): 689-700.

Wang, Z., Gerstein, M. and Snyder, M., 2009. RNA-Seq: a revolutionary tool for transcriptomics. Nature reviews genetics, 10(1): 57-63.

Wu, B. et al., 2019. The performance of biochar-microbe multiple biochemical material on bioremediation and soil micro-ecology in the cadmium aged soil. Science of the total environment, 686: 719-728.

Wu, Y.-w., Zhang, J.-c., Wang, L.-j. and Wang, Y.-x., 2017a. A rock-weathering bacteria isolated from rock surface and its role in ecological restoration on exposed carbonate rocks. Ecological Engineering, 101: 162-169.

Wu, Y., Zhang, J. and Guo, X., 2017b. An Indigenous Soil Bacterium Facilitates the Mitigation of Rocky Desertification in Carbonate Mining Areas. Land Degradation \& Development.

Wu, Y., Zhang, J., Guo, X., Wang, Y. and Wang, Q., 2017c. Isolation and characterisation of a rock solubilising fungus for application in mine-spoil reclamation. European Journal of Soil Biology, 81: 76-82.

Wyman, S.K., Jansen, R.K. and Boore, J.L., 2004. Automatic annotation of organellar genomes with DOGMA. Bioinformatics, 20(17): 32523255.

Xiao, B., Lian, B. and Shao, W., 2012a. Do bacterial secreted proteins play a role in the weathering of potassium-bearing rock powder? Geomicrobiology Journal, 29(6): 497-505.

Xiao, B., Lian, B., Sun, L. and Shao, W., 2012b. Gene transcription response to weathering of K-bearing minerals by Aspergillus fumigatus. Chemical Geology, s 306-307(1): 1-9.

Xiao, B., Lian, B., Sun, L. and Shao, W., 2012c. Gene transcription response to weathering of K-bearing minerals by Aspergillus fumigatus. Chemical Geology, 306: 1-9.

Zhang, X.Q. et al., 2013. Genome-wide analysis of DNA methylation in rat lungs with lipopolysaccharide-induced acute lung injury. Molecular Medicine Reports, 7(5): 1417-1424.

Zhou, J., Bruns, M.A. and Tiedje, J.M., 1996. DNA recovery from soils of diverse composition. Applied and environmental microbiology, 62(2): 316-322.

\section{Figures}



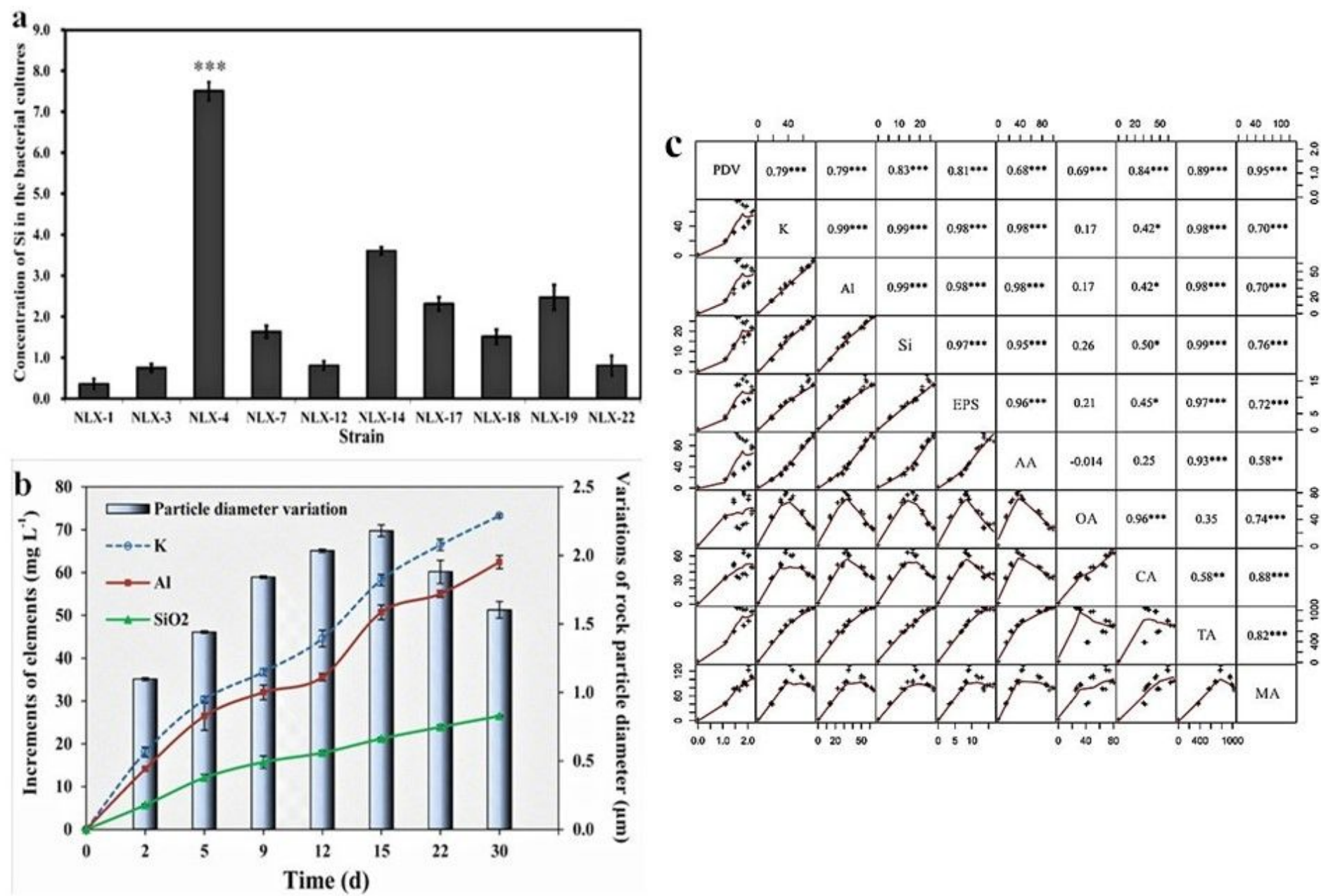

Figure 1

a) The fermentation results of different bacterial strains (10 strains in total) for 7 days showing the final concentration of Si released during the fermentation of rock samples; b) the final concentrations of released elements $\mathrm{K}+$, Al3+ and Si4+ from the rock samples by the NLX-4 strain and particle diameter variations (PDV); c) Pearson's correlation analysis of PDV of the fermented rock samples; exopolysaccharides (EPS); acetic acid (AA); oxalic acid (OA); citric acid (CA); tartaric acid (TA); malic acid (MA). Symbol *, **, and *** represent that the correlations are significant at 0.5, 0.01, and 0.001 levels, respectively. Error bars represent the standard deviation $(\mathrm{n}=3$ ). 

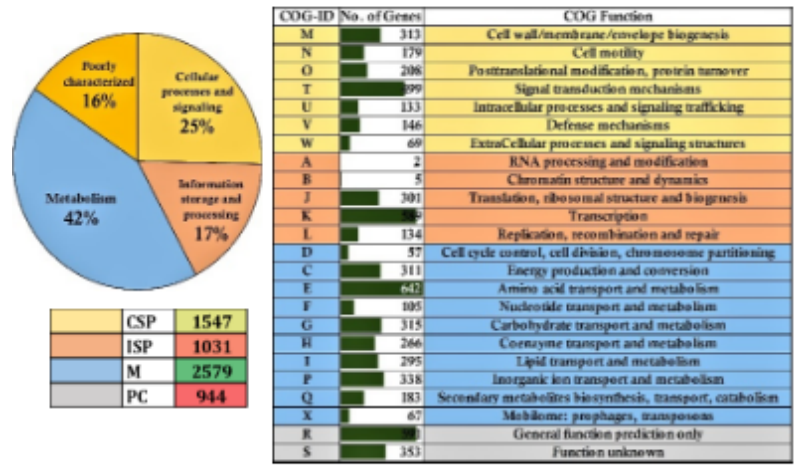

\begin{tabular}{|c|c|}
\hline \multicolumn{2}{|l|}{$>10$ copies in the NLX-4 genome } \\
\hline Glutathone S-transficrase & 19 \\
\hline RND efflex purp & 19 \\
\hline Abohol dehydrogemase & 18 \\
\hline Ouler menbrane efflix & 17 \\
\hline AseC-type HTH domain & 16 \\
\hline NUDIX hydrolase domin & 16 \\
\hline Outer membrane porin & 16 \\
\hline $\mathrm{ABC}$ transponter, permease & 15 \\
\hline FecR proten & 15 \\
\hline AAA+ATPase domin & 14 \\
\hline Cytoclrome $\mathrm{e}$-like domain & 14 \\
\hline $2 \mathrm{Fe}-2 \mathrm{~S}$ ferredoxin-type & 13 \\
\hline Crotomse superfinily & 13 \\
\hline EAL doman & 13 \\
\hline Helicase, C-terminal & 13 \\
\hline NAD-dependent epinerase & 13 \\
\hline Pif assembly chaperonx & 13 \\
\hline Sugar transporter, & 13 \\
\hline Acyl-CoA axidase/ & 12 \\
\hline Baclerial periphsmic spennaline & 12 \\
\hline Hexapeptide repeat & 12 \\
\hline MarR-type HTH domain & 12 \\
\hline Metallo-beta-hctamase & 12 \\
\hline Yjof/YER057cUK114 famly & 12 \\
\hline Acyt-CoA dethydrogenase & 11 \\
\hline Apta Beta bydrohse fold & 11 \\
\hline FADNAD(P)-binding domain & 11 \\
\hline MerR-type HTH domin & 11 \\
\hline Thiolase & 11 \\
\hline Acrillavin resistance protcin & 10 \\
\hline Aminotransferase chass V domin & 10 \\
\hline Amibotransferase chass-III & 10 \\
\hline Biotinlpoyl atbchmex & 10 \\
\hline Glycosylitranferase 2 ike & 10 \\
\hline bochorismatase-like & 10 \\
\hline NodB homology domain & 10 \\
\hline Ouler membrane usber & 10 \\
\hline Phospholpid/gycerol acyltransferase & 10 \\
\hline RNA polymerase sigm fictor 54 & 10 \\
\hline Twin-arginix transbcation pathway & 10 \\
\hline
\end{tabular}

\section{Figure 2}

a) Genome wide distribution of Prokaryotic Orthologous Groups (COG) where CSP: Cellular process and signaling 25\% (1547); ISP: Information storage and processing 17\% (1031 genes); M: Metabolism 42\% (2579 genes); PC: poorly characterized 16\% (944 genes). b) The listed table illustrates the individual classification of genes in different COG classes which are differentiated based on the color as per pie diagram 2A. c) Pictorial illustration of genes occurring $>50$ copies, $>20$ copies and $>10$ copies in the Pseudomonas sp. NLX-4 strain genome. 


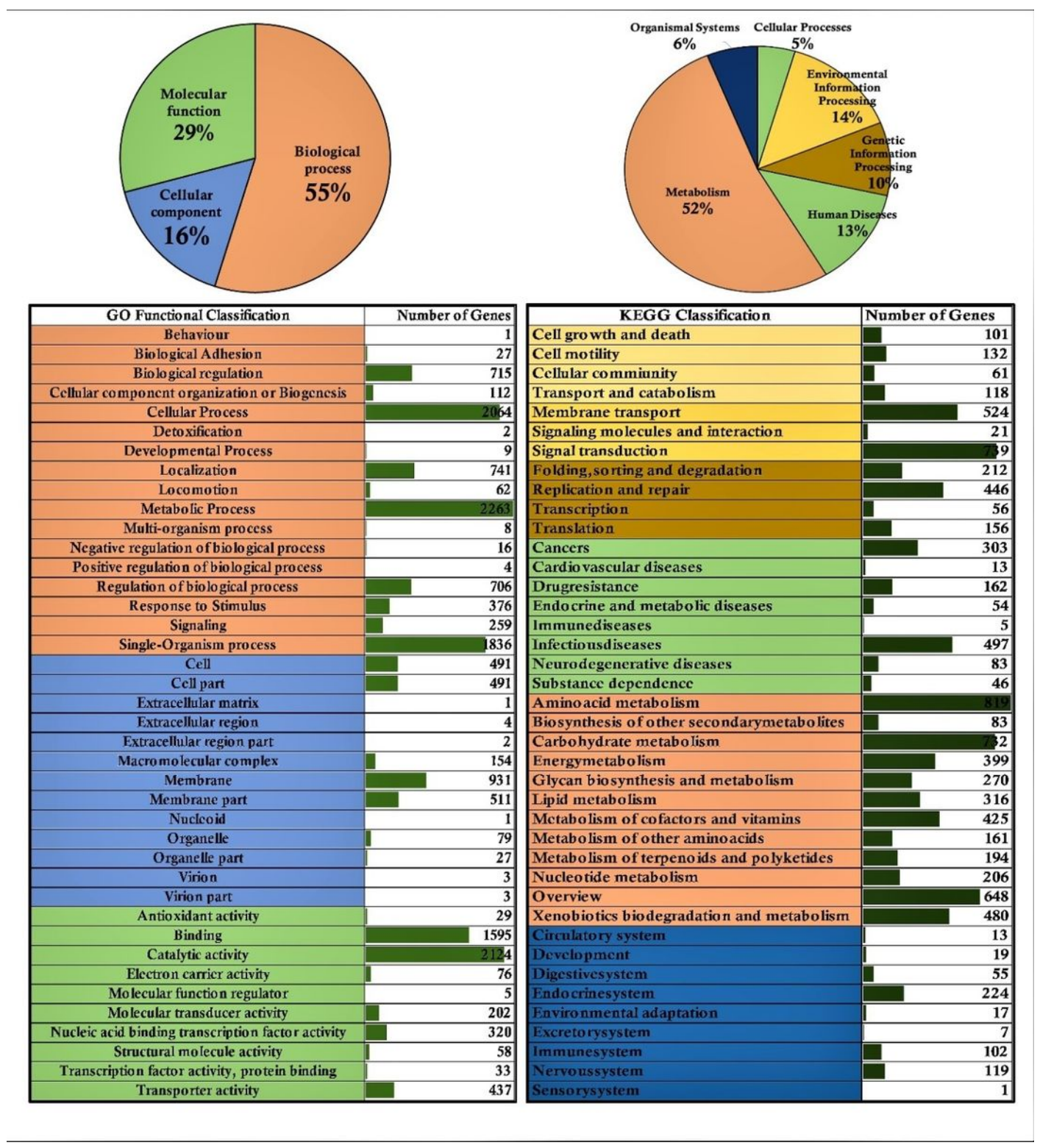

\section{Figure 3}

Pictorial illustration of genome-wide distribution of Pseudomonas sp. NLX-4 strain genes against gene ontology (GO) and KEGG database [Note: Pie chart illustrates complete distribution of genes and tabular illustration lists the distribution of genes in individual classes. The color schema uses in pie chart is also applied for the tabular representation]. 
a

\begin{tabular}{|c|c|}
\hline KEGG-Pathway & No of Genes \\
\hline Cell growth and death & 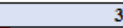 \\
\hline Cell motility & 32 \\
\hline Membrane transport & 47 \\
\hline Sigmal tramsduction & 53 \\
\hline Folding, sorting and degradation & 14 \\
\hline Replication amd repair & 11 \\
\hline Tramseription & \\
\hline Tramslation & 49 \\
\hline Amim acid metabolism & 60 \\
\hline Biosynthesis of other secondary metabolites & 11 \\
\hline Carbohydrate metabolism & 65 \\
\hline Energy metabolism & 53 \\
\hline Global and overview maps & 158 \\
\hline Glvean biosynthesis and metabolism & \\
\hline Lipil metabolism & 24 \\
\hline Metabolism of cofactors and vitamins & 37 \\
\hline Metabolism of other amim acids & 33 \\
\hline Metabolism of terpenoids and pokkketides & 17 \\
\hline Nucleotile metabolism & 24 \\
\hline Tembbiotics biodegradation: & 18 \\
\hline wiron & \\
\hline
\end{tabular}

b

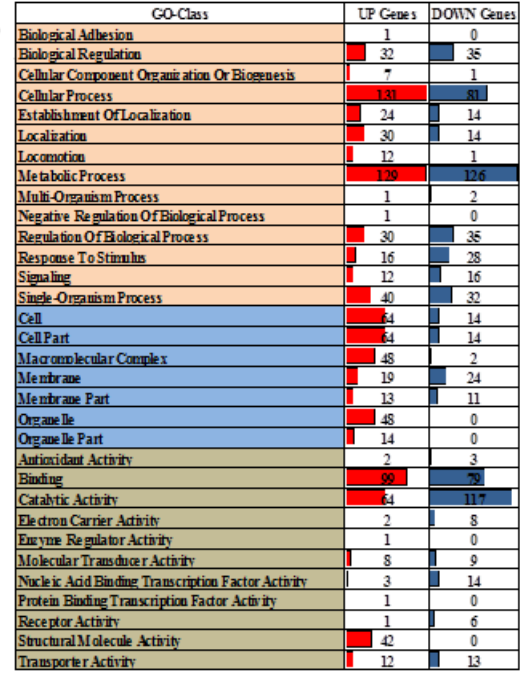

\section{Figure 4}

The total number of differentially expressed significant genes obtained from RNA-Seq with a) Enriched KEGG pathways and b) Gene ontology (Biological process, cellular component, and molecular function).

\section{Supplementary Files}

This is a list of supplementary files associated with this preprint. Click to download.

- 72GraphicAbstract.tif

- SupplementaryInformation.docx 